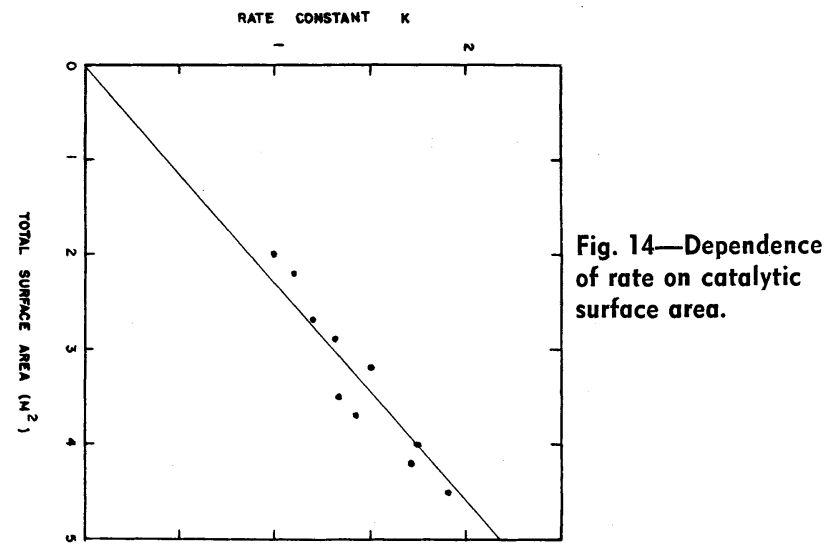

that $d$, the density, is either constant or can only increase till it reaches the density of solid nickel. A comparison of the number of particles at $i=1$ and at $i=5$ gives a ratio of 4 . Thus, the process of agglomeration, which results in a decrease in the number of particles at the end of a nickel reduction in which $\mathrm{Fe}^{++}$is used as a catalyst, probably continues in the early densifications when the particles are still fine. The critical size of the particles at which agglomeration ceases depends on many factors, of which degree of agitation is probably very important.

\section{Summary}

Both theory and practice show that the reduction of nickel proceeds to completion only when the $\mathrm{NH}_{3} / \mathrm{Ni}$ molar ratio is in the range of about 1.5 to 2.5 .

The reaction is catalyzed by $\mathrm{Fe}^{++}$, resulting in the formation of metallic nickel nuclei, which further catalyze the reaction, causing an acceleration of the reaction rate (autocatalysis). The acceleration may be explained by assuming a constant rate of formation of the nuclei and a direct proportionality between the rate of reduction and the number of the nuclei.

The nuclei probably not only grow during reduction, but also agglomerate into larger sized particles and gradually assume the spherical form. When a certain critical size is reached, the agglomeration process ceases and the particles grow symmetrically in all directions. At this stage, the rate of reduction is found to be directly proportional to the calculated surface area of the nickel particles.

Apart from the effect of catalysts, the reaction rate is found to be proportional to the $\mathrm{H}_{2}$ partial pressure to the first order (approximate), to be independent of the nickel concentration in solution, and to have

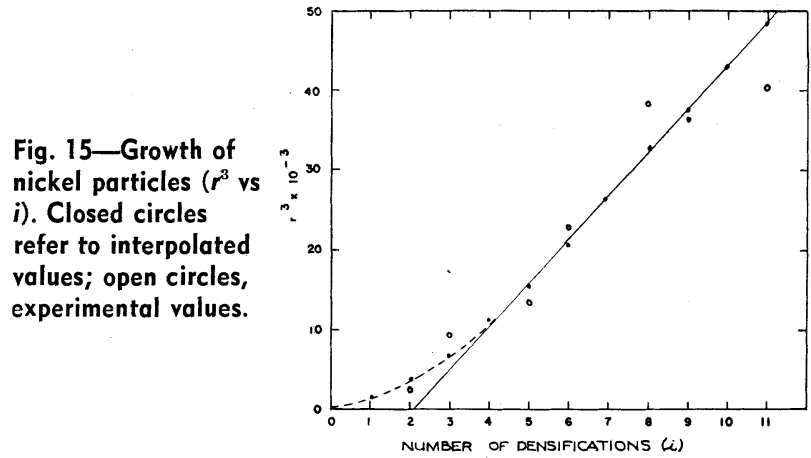

an apparent energy of activation of between 5 and 15 kcal.

\section{Acknowledgments}

The authors wish to thank Sherritt Gordon Mines Ltd. for providing the opportunity and encouragement to work on this problem and for permission to publish the results. They wish to express their gratitude to F. A. Forward and the late S. Nashner for their interest and support of the work, to thank J. Halpern for his contribution to the treatment of the kinetics of the $\mathrm{Fe}^{++}$catalyzed reaction, $\mathrm{R}$. L. Benoit for his contribution to the treatment of the thermodynamics of the reduction of nickel in ammoniacal solutions, and J. P. Auffray for his part of the work on the nickel particle growth problem.

\section{References}

1 F. A. Forward: Ammonia Pressure Leach Process for Recovering Nickel, Copper and Cobalt from Sherritt Gordon Nickel Sulphide

Concentrate. CIM Trans., 1953, vol. 56, pp. 363-370.
2 F. A. Forward: Production and Properties of High Purity Nickel Powder. Bulletin Institute of Metals, 1954, vol. 2, pp. 113-116.

${ }^{3}$ V. N. Mackiw: Formation of Sulphur-Oxygen Compounds during the Oxidation of Sulphide Minerals in Ammoniacal Solution by Oxygen Under Pressure. CIC Conference, Windsor, 1953. V. N. Mackiw, W. C. Lin, and W. Kunda: The Precipitation of Metallic Nickel from Aqueous Solutions in the Sherritt Gordon Process. CIC Conference, Toronto, 195

$\overline{5}$ F. A. Forward and V. N. Mackiw: Chemistry of the Ammonia Pressure Process for Leaching Nickel, Copper and Cobalt from Sher ritt Gordon Sulphide Concentrates, AIME Trans., 1955, vol. 203, pp. Th -463; Journal of Metals, March 1955

CIM Trans. 1955 ol. 58, pp. $212-226$

A. Schaufelberger: Precipitation of Metal from Salt Solution by Reduction with Hydrogen. Mining ENGINEERING, 1956, vol. 8, No. 5, pp. 539-548.

8 M. Pourbaix: Thermodynamics of Dilute Aqueous Solutions.

Edward Arnold and Co. London, 1949. P. Haase and Son. Copenhagen, 1941.

10 Research and Development Laboratory, Sherritt Gordon Mines Ltd., Fort Saskatchewan, Alberta, Canada. Unpublished data.

11 H. A. Pray, C. E. Schweickert, and B. H. Minnich: Gas Solubilities in Aqueous Solutions at Elevated Temperatures and Pressures.

Industrial and Engineering Chemistry, 1952 , vol. 44, p. 1146.
12 D. S. Davis: Water Solubility charts of Helium, Hydrogen, Nitrogen and Oxygen. Chemical Engineering, 1954, vol. 61, No. 2, p. 228.

Discussion of this paper sent (2 copies) to AIME by Aug. 1, 1957 will appear in AIME Transactions Vol. 212, 1958, and in JourNaL o Metals, October 1958 .

Technical Note

\title{
Bismuth in Copper Grain Boundaries
}

\author{
by C. W. Spencer, R. A. Rummel, and F. N. Rhines
}

C. W. SPENCER, Junior Member AIME, formerly Research Metallurgist, Metals Research Laboratory, Carnegie Institute of Technology, is associated with the School of Chemical and Metallurgical Engineering, Cornell University, Ithaca, N. Y. R. A. RUMMEL and F. H. RHINES, Member AIME, are Senior Technician, Metals Research Laboratory, and Alcoa Professor of Light Metals, Dept. of Metallurgical Engineering, respectively, Carnegie Institute of Technology, Pittsburgh.

TN 407E. Manuscript, Nov. 30, 1956.
S PECIMENS of five cast $\mathrm{Cu}-\mathrm{Bi}$ alloys, containing $4.68,0.53,0.043,0.0064$, and 0.0025 wt pct $\mathrm{Bi}$ and cast pure copper were subjected to a bend test to determine their relative ductility. Using metallographic methods the structures of the fractured surfaces were compared with those of the polished cross sections. Embrittlement was found to be associated with the presence of a second phase in the grain boundaries although, in the lower bismuth 